\title{
Los derechos humanos
}

\section{y los pueblos oprimidos. Reflexiones histórico-teológicas*}

\author{
Jon Sobrino. \\ Centro de Reflexión Teológica, \\ San Salvador
}

\section{Introducción: la paradoja}

En esta conferencia quisiera hacer algunas reflexiones sobre el problema de los derechos de los pueblos oprimidos en el contexto del L Aniversario de la Declaración Universal de Derechos Humanos.

Con ocasión de esta celebración es justo celebrar los avances que la humanidad ha realizado en materia de derechos humanos, frulos de reivindicaciones hislóricas', y su continuo desarrollo, de modo que se puede hablar ya de diversas generaciones de derechos humanos. En El Salvador conocemos muy bien la importancia de estos avances, aunque sea sub specie contrarii, pues durante largos años de opresión y represión se han violado los derechos más fundamentales del ser humano por lo que loca a la vida, a la seguridad y a la libertad, y quienes los han defendido han pagado un alto precio. Marianella García Villa y Herbert Anaya Sanabria, direclores, ambos, de la Comisión de Derechos Humanos no Gubernamental, fueron asesinados en 1983 y 1987. El padre Segundo Montes, S. J., director del Instilulo de Derechos Humanos de la UCA, fue asesinado en 1989. Y muchos otros que trabajaron por la defensa de la vida murieron lambién asesinados, desde Monseñor Romero al P. Ignacio Ellacuría.

* Conferencia pronunciada el 3 de marzo de 1998 en la Universidad de Deusto, Bilbao. dentro del ciclo de conferencias sobre derechos humanos, organizado por el Foro Deusto, el Colegio de Abogados de Vizcaya y el lnstituto de Derechos Humanos Pedro Arrupe de la Universidad de Deusto. El ciclo se organizó con motivo del $L$ Aniversario de la Declaración Universal de Derechos Humanos.

I. La Charia Magna (1215), Bill of righis (1689). Declaración de derechos de Virginia (1776), Declaración de los derechos del hombre y del ciudadano $(1789,1793) \ldots$ 
No vamos a insistir, pues, en lo positivo y necesario que hay en el desarrollo teórico de los derechos humanos, en el avance en la legislación en esa dirección $y$, sobre todo, en el respeto real de ellos. Pero sí queremos mencionar una paradoja, que, vista desde pueblos como El Salvador, resulta chocante y, en definitiva, escandalosa. Esta consiste en que hay avances en la teorización y formulación de los derechos humanos, sobre todo de los derechos individuales; pero visto el mundo en su totalidad, y teniendo en mente la vida de los pueblos y de las grandes mayorías, la situación real de esa vida no mejora al ritmo de los avances teóricos. $Y$ a veces no sólo no nejora a ese ritmo, sino que incluso empeora. Peor aún, los derechos humanos universales pueden convertirse en normatividad absoluta abstracta, que no eslá en favor de las mayorias populares y de los países del tercero y cuarto mundo. Incluso pueden defender veladamente lo adquirido o adquirible por los más fuertes. Así lo afirmaba I. Ellacuría en un curso que dio en 1989, poco antes de su asesinato:

El problema de los derechos humunos es un problema no sólo complejo, sino ambiguo pues en él no sólo confluye la dimensión universal del hombre con la situación real en la cual desarrollan su vida los hombres, sino que propende a ser utilizado idcológicamente al servicio no del hombre y de sus derechos, sino de los intereses de unos u otros grupos?.

Para evitar esos graves peligros, Ignacio Ellacuría exigía una adecuada historización de los derechos humanos y pedía a los estudiosos tcorizarlos a partir del tercer mundo y sus pueblos, así como la teología de la liberación lo había hecho con temas teológicos, al tratar -desde la realidad del tercer mundo- del Dios de la vida, de la lglesia de los pobres, de la salvación como liberación...

A esto quisieran ayudar, modestamenle, estas reflexiones, analizando los derechos humanos desde la perspectiva de los pueblos oprimidos. En una primera parte, analizaremos dos elementos importantes de lo que, en sentido amplio. podemos llamar la episfemología lundamental para reconocer los derechos de los pueblos oprimidos: (1) saber escuchar el clamor de las víctimas y (2) despertar del sueño de inhumanidad en que queda sumida la conciencia colectiva. Lo primero aparece con claridad en la situación del puchlo de Isruel en el éxodo -importante por ser el momento fundante de la tradición biblica (no muy presente en la tradición occidental). Lo segundo aparece también con claridad en lo ocurrido en el siglo XVl a los pueblos indigenas latinoamericanos y lá reacción de La Española -imporlante porque determinó en buena medida la historia de occidente y su ambigua tradición de derechos humanos. En una segunda parte analizaremos la realidad actual como realidad de pueblos

2. I. Ellacuria, "Historización de los derechos humanos desde los pucblos oprimidos y las mayorias populares", ECA 502 (1990) 590. 
crucificados, que expresan la verdad última de la situación de los derechos humanos, su cuestionamiento y la dirección que éstos deben tomar para ser derechos de toda la familia humana, no sólo de individuos, grupos o países.

Para terminar esta introducción insistimos en que abordamos los derechos humanos como aquello que remite a un ámbito globalizante de la realidad. No analizaremos, por lo tanto, el contenido concreto de lo que hoy se entiende convencionalmente por "derechos humanos". Dando esto por sentado, nos centramos en lo más abarcador y central: "el problema radical de los derechos humanos es el de la lucha de la vida en conira de la muerle, la busca de lo que da vida frente a lo que la quila o da muerie" 3 . Veamos lo que podemos aprender sobre ello desde el éxodo y La Espanola.

\section{La experiencia primaria: escuchar el "clamor de las víctimas"}

Es evidente que sin institucionalización de los derechos humanos la experiencia primaria ante la realidad de las víclimas -indignación y compasión- se torna ineficaz. Pero, a la inversa, sin esa experiencia primaria no se pone en marcha el proceso de reconocer lo que es debido a los humanos; y, además, si no se mantiene esa experiencia original a lo largo del proceso, los derechos humanos quedan amenazados por graves peligros: abstracción ineficaz y manipulación en favor del fuerte en contra del débil. Por eso comenzamos con la experiencia primaria.

Los seres humanos, el menos en lengua castellana, hemos fraguado la expresión "¡no hay derecho!". Con ello expresamos un radical no deber ser, cuyo origen no proviene de colejar la realidad con alguna normaliva, sino de caplar lo indebido que se hace a unos seres humanos por parte de olros. $\mathrm{Y}$ lampoco proviene sólo, aunque éstas lo presupongan, de reivindicaciones hislóricas por alcanzar algún derecho que todavía no hubiera sido reconocido. A la base de la experiencia de los derechos humanos está un hecho más primario: la masiva existencia de víctimas4.

3. I. Ellacuría, op. cir. p. 593.

4. Li injusta opresión de unos por otros, la victimizacion, cs lo que hace exclamar "no hay derecho". Pero cso ocurre lambién ante manejos inhumanos de cosas posiblemente licilas en si mismas (el volumen de gastos en armamento, amnistías precipitadas, monopolios de información) y anlc clamorosos agravios comparaivos (los recursos invertidos para hacer posible un partido de fúlbol, que pucden llegar a represenlar un considerable porcentaje del presupuesto nacional de un pais en la miscria). También en cslos casos resucna cl "no hay derccho". Y que resucne o no es un indiec de la salud moral de una sociedad. 


\subsection{El éxodo: dialéctica y parcialidad desde las víctimas}

Primera proposición: El contenido de los derechos humanos se descubre, dialécticamente, desde su violación en las víctimas. Esos derechos expresan, ante todo, las necesidades básicas de la vida y de la supervivencia; son derechos de todo un pueblo; hay que trabajar por ellos y defenderlos activamenle, $y$, por ello, hay que enfrentar a quienes los conculcan.

a) La dialéctica: los derechos negados, el clamor de las víctimas. La Biblia no usa terminología ni conceptualización de derechos humanos en el sentido moderno, ni conoce varios de ellos, pero sí exige el cumplimiento del derecho fundamental a la vida y denuncia con vigor sus violaciones, como lo muestra la tradición profética. Lo importante para nuestro propósito es saber cómo surge la experiencia primaria de que algo se le debe al ser humano; en otras palabras cómo fundamenta la Biblia dichos derechos. $\mathrm{Y}$ la respuesta nos parece importante hasta el día de hoy.

Pues bien, la reflexión sobre lo que es debido al ser humano comenzó al captar lo que se hace con él indebidumente, es decir, a través de la captación de su contrario. Esa reflexión comenzó con lo ocurrido en Egipto - sea cual fuere su faclualidad-, el acontecimiento fundante para Israel. Varios siglos después de los hechos, el autor del relalo lo formula así: "Bien vista tengo la aflicción de mi pueblo en Egipto y he escuchado su clamor en presencia de sus opresores; pues ya conozco sus sufrimientos. He bajado para librarle de la mano de los egipcios y para subirle de esta tierra a una tierra que mana leche y miel" (Ex 3, 7-8).

Todo comienza, pues, con unos clamores. Dios (o Moisés) escucha clamores de seres humanos, condena el hecho de que unos seres humanos sean oprimidos por otros, es movido a compasión, baja a liberarlos, enfrenta y anula al faraón. En lenguaje religioso se expresa aquí la experiencia primordial: el "no hay derecho" y la reacción práxica "he bajado a liberarlo". Y el texto lo expresa claramente: Dios (o Moisés) reacciona porque la realidad es inhumana en sí misma, no porque se haya violado una legislación previa o alguna prescripción suya, ni porque los isarelitas puedan apelar a ellas.

Eslo quiere decir que el pueblo de Israel no lundamentó los derechos humanos esencial y universalmente, sino histórica y dialéclicamente. Es cierlo que en la Biblia se asientan tambićn, de hecho, las bases para tal fundamentación universal - "lodos los seres liumanos han sido creados a imagen de Dios" (Gen $1,27)^{5}$, como aparece en el relato de la creación, pero ese viene después. Ese

5. En el Nuevo Testamento este lipo de fundamentación está posibilitada por el acontecimiento de Cristo. Pablo dice que en Crisso Jesis "ya no hay judio ni genlil, varón o mujer, librc o esclavo" (Gal 3.28), nunque no hay que olvidar que en ICorintios 12, 13 deja de mencionar el binomio varón-mujer por la convulsión sucial que eso generaba en su liempo. Y esta fundamentación se radicalizarí a partir de la 
modo de argumentar a partir de la proveniencia del ser humano es semejante a la argumentación de la Declaración Universal: "todos los seres humanos nacen libres e iguales en dignidad y derechos" (Art. 1). Esto es bueno y necesario, pero no hace superflua la experiencia original, sino lodo lo contrario: ésta debe estar presente en el proceso de universalización.

Hemos recodardo que los derechos humanos se captan dialécticamente -a partir de la conculcación de lo humino- porque sigue siendo fundamental hasta el día de hoy, aun cuando en nuestro mundo ya existan declaraciones de derechos humanos. Y decimos que es fundamental porque ese mismo mundo pretende muchas veces, de formas burdas o sutiles, que no aflore o se sofoque el "no hay derecho", que es lo que pone en marcha todo el proceso. Es evidente que hay una gran Iragedia en los Grandes Lagos, en Argelia, en Timor del Este, pero ni su captación ni su solución dependen, en lo esencial, de colejarla con las declaraciones de los derechos humanos, sino de la indignación y compasión ante la tragedia en sí misma. Sobre ello volveremos en la segunda parte, pero digamos ya desde el principio que para hacer la experiencia primaria es necesario estar en la realidad de las victimas, como lo dice el canto de los negros esclavos: “Were you there when they crucified my Lord?". Fuera de ese lugar, en cuanto realidad sustancial, no sólo en cuanto ubi cátegorial, con dificultad se captará lo que son víctimas y lo que son derechos.

b) La parcialidad: la primacía de las "víctimas" sobre el "rodo". Ya hemos dicho que en los derechos humanos todo comienza con víctimas, no simplemente con seres humanos. Pues bien, desde ellas Israel insistió en la parcialidad, como hermenćutica, diríamos hoy, para comprender el todo de la realidad.

Desde ellas definió a Dios desde una perspecliva parcial. "Padre de huérfanos y viudas eres tú", dice el Salmo 68, 6. La verdadera confessio Dei de Israel consiste en la aclamación: "en li el huér[ano encuentra compasión"6. Eslo significa que Dios es, anle todo, defensor de las víctimas, y sólo después será confesado como creador de todo. Y aunque el tema de Dios no sea el de esia conlerencia, recordar que a Dios se lo teorizó desde la parcialidad de las víctimas ayuda a comprender cómo se teorizó el derecho.

En Israel y en los pucblos circundantes. éste no surgió como conclusión a la que se llega a partir de una comprensión universal de la naturaleza humana, sino que surgió para defender a las víctimas, quienes sin esa realidad llamada

encarnacion: lo humano, por serlo $\rightarrow$ sin añadidos- es capaz de ser asumido por Dios, de ser divinizado, con lo cual sc proclama la radicalidad de la dignidad de lo humano.

6. H. Wolf, Dodekapropheten, 1, p. 304. 
"derecho" son presas todavía más fáciles de los poderosos. "Cuando en la hisloria se ideó la función de un juez o lo que después llegó a llamarse juez, fue exclusivamente para ayudar a quienes, por ser débiles, no pueden defenderse; los otros no lo necesitan ... Cuando la Biblia habla de Jahvé "juez" o del juicio cuyo sujeto es Jahvé, piensa precisamente en salvar de la injusticia a los oprimidos"7. "La justicia del rey no consiste primordialmente en emitir un veredicto imparcial, sino en la protección que preste a los desvalidos y a los pobres, a las viudas y a los huérfanos" universalidad, que históricamente es parcial al poderoso, es lo que está en el origen del derecho en Israel. Y ello porque se trata de defender a víctimas.

Recordamos la parcialidad del derecho porque, de nuevo, es de suma actualidad. El símbolo actual de imparcialidad de la justicia - la mujer de los ojos vendados que no admite acepción de personas, y ojalá así fuese- es más occidental que biblico. En la Escritura no es así. La figura ideal del rey justo esperado tiene los ojos abierlos: mira directamente al pobre y al oprimido para defenderlos. Bien sabemos que en la realidad la ley es parcial, sólo que hacia los poderosos, como lo dijo Monseñor Romero, citando a un campesino. "La ley es como la serpiente. Sólo pica al que está descalzo". Contra la imparcialidad espúreamente parcial, las víctimas remiten a la verdadera parcialidad.

c) La vida de un pueblo. Además de la captación dialéctica y de la parcialidad, el éxodo ofrece una "constelación" de realidades atrededor de los derechos humanos, importantes hasta el día de hoy, aunque, obviamente, deban ser historizadas.

En primer lugar, se trata de derechos básicos que deben salisfacer las necesidades de la vida: poder vivir (no matar a los niños varones de los israelitas), poder dominar la vida (en una lierra que se lo facilite), vivir en libertad (superar la esclavitud). Ya lo hemos dicho antes en forma global: promover los derechos humanos es, ante lodo, promover la vida y combalir la muerte. Violar los derechos humanos es, ante todo, promover la muerte y combalir la vida. $Y$ añadamos que vida y muerte se refieren no sólo a la subsistencia, sino también a la dignidad y a la cultura fundamentales de los pueblos.

Volveremos sobre este punto, que es el fundamental en el mundo actual, pero digámoslo desde ahora. El paradigma de Egipto es evidente en países como El Salvador, pero no suele serlo en países de abundancia, en los que hablar de derechos humanos sugiere el goce de libertades políticas y civiles, de libertad de expresión y de culto... $Y$ es que la humanidad se divide en dos grandes grupos:

7. P. Miranda, Marx y la Biblia, Sálamanca, 1972, p. 140s.

8. J. Jeremias, Teología del Nuevo Testameno I, Salamanca, 1974, p. 122. 
aquellos que ya dan la vida por supuesto y aquellos que lo que no dan por supuesto es precisamente la vida. Para éstos, la mayoría de la humanidad, el mayor problema es la vida amenazada, y es también su mayor utopía y su mayor derecho, es "ese mínimo que es el máximo don de Dios: la vida", como decía Monseñor Romero. Este derecho a la vida es lo que exige urgente historización. En palabras de l. Ellacuría, la mera vida biológica

puede parecer algo sobreentendido en los países más ricos, que lienen asegurado este derecho..., pero no es así en la mayor parte de los países, donde se hace sumamenle poblemálico conservar la vida biológica, sea por la extrema pobreza, sea por la represion y la violencia. Para la mayor parte de la humanidad... no se dan las condiciones reales para poder seguir viviendo biológicamente - hambre y falta de trabajo".

En segundo lugar, se trata de los derechos de un grupo social (el relato del Exodo habla, idealizadamente, de un pueblo), es decir, son derechos de mayorias (no primariamente de individuos) y son derechos de un pueblo. En este modo de ver las cosas puede estar actuante el tipo de antropologia, más comunitaria y societal que individualista, de pueblos antiguos, y está actuante, sin duda, el hecho teológico de que la relación de Dios acaece en directo con todo un pueblo. Pero. en cualquier caso, esta perspectiva es importante para comprender los derechos humanos desde "la lógica de las mayorías" y desde "la lógica de los pueblos oprimidos".

Mal está que se violen los derechos de los individuos, pero es peor que se violen los de tocio un pueblo o los de lodo un continenle. $Y$ ello no sólo por la obvia dimensión cuantilativa del problema, sino porque cuando se trata de los derechos de los pueblos las raíces de su violación suelen ser más hondas y también su encubrimiento. En estos casos, el encubrimiento llega a tal grado que ni siquiera se usa el lenguaje convencional de violación de derechos humanos, a no ser que ocurra en los antiguos regimenes comunistas. Si en Cuba, por ejemplo, un intelectual no goza de libertad de expresión, eso es considerado no sólo como algo malo, sino como violación a sus derechos humanos. Pero cuando grandes mayorías en el tercer mundo carecen de vivienda, salud, educación, cuando de treinla a cuarenta millones de seres humanos mueren anualmente de hambre o de enfermedades relacionadas con ella, cuando elnias enteras quedan sin acceso a decir su palabra, entonces, habrá críticas y lamentos (sinceros o hipócritas, según los casos), pero no se usa el lenguaje de derechos humanos, no se dice que se ha conculcado el derecho a la vida de pueblos enteros. De esa forma, no hay que pedir cuentas a ningún responsable ni hay que reaccionar con la urgencia y magnitud que exige el caso.

9. Op. cil., p. 59.3 . 
En tercer lugar, esos derechos deben ser no sólo reconocidos, sino defendidos, es decir, hay que rrabajar y luchar por ellos. A la experiencia original le compete la indignación, pero también el volcarse a una praxis (aunque en el éxodo esıo quede muy estilizado, atribuyendo a Dios, o a Moisés, la praxis fundamental, sin analizar la base material de tal praxis)ı.

Eslo quiere decir que, para caplar lo que es un derecho humano, no basta un concepto puramente leórico, sino que se necesita un concepto teórico-práxico. Como sucede en toda relación entre teoría y praxis, en la medida en que se los va defendiendo, se va caplando en qué consisten realmente. Al propiciar activamente la vida de los prividos de vida y luchar contra la negrura de la muerte, se va comprendiendo desde dentro - por la gran dificultad de esa lucha- lo que es el derecho a la vida, lo que son los derechos de los pobres y su jerarquización. Nada hay mejor para saber qué son los derechos humanos, en qué jerarquía eslán y quiénes los necesitan con mayor urgencia que ponerse a defender la vida de los pobres.

En cuarto lugar, el éxodo permanecerá como referente a lo largo de la historia de Israel en su credo y también en su legislación social. No sentó jurisprudencia en sentido técnico, pero introdujo un elemento y una perspectiva esencial en la legislación de lsrael: "Rccuerda que tú también fuiste forastero en Egiplo" (Di 5, 6; Ex 20). El mal y el bien, lo que se debe hacer y lo que no se debe hacer, quedan siempre remitidos a la experiencia original: nadie puede ser maltratado en Israel, ni de fuera ni de dentro, porque "forasteros fueron ustedes en lierra de Egiplo".

La conclusión de todo lo dicho en este apartado es que hay que volver siempre a lo que puso en marcha la conciencia de que algo le es debido al ser humano. Ese origen deberá ser teorizado e historizado, pero deberá permacener a lo largo del proceso para crecer en humanidad y para evilar la paradoja de la que hablábamos al comienzo. En una palabra, no hay avance verdadero si no se mantiene el original "ino hay derecho!".

\subsection{La Española: ceguera y autojustificación de los victimarios}

Segunda proposición: Correlativamente a víclimas hay victimarios de pueblos enteros. Aquéllos no sólo conculcan derechos humanos, sino que buscan justificaciones tcóricas para hacerlo impunemente. Lo más grave es que suelen estar sumidos en una ceguera esiruclural, dificilmente superable.

10. Lo que hay que mantener del paradigma del Exodo es la necesidad de la praxis y aun de la lucha, no, evidentemente. los modos guerreros y crueles en contra de los cgipcios que se lc atribuyen a Dios. 
a) Pucblos destruidos. Otro momento importante a tener en cuenta en la teorización de los derechos humanos es lo ocurrido hace cinco siglos en lo que hoy llamamos América. Así como en el apartado anterior nos hemos centrado en lo que ocurre a las víctimas, nos centramos ahora en los victimarios y su comportamiento. Y también sobre esto hubo en la época un juicio religioso cristiano.

El hecho es indisculible. Poco después de la llegada de los españoles, la vida de los indigenas comenzó a desaparecer y pucblos enteros, con sus gentes, culturas, tradiciones y religiones, fueron destruidos. Las causas fueron múltiples: guerras, tratos crueles, enfermedades importadas contra las que los nativos no estaban inmunizados, trabajos durísimos, suicidios por desesperación, migraciones inhumanas... A veces los propios indígenas colaboraron con los invasores para sacudirse el yugo de opresores locales - lo cual para algunos historiadores es un dalo explicativo fundamental de la masividad del drama. No es, pues, justo acusar de lo sucedido unilateralmente a unos, pero tampoco se puede ignorar la crudeza del hecho fundamental y sus responsables: en el nuevo conlinente luvo lugar un inmenso acto de depredación, expolio y destrucción por parte de españoles y portugueses. Unos selenta años después, la población indígena estaban en vias de exlinción, quedó reducida a un quince por ciento.

Y esto no fue casual. Aunque no se pretendiese en directo, la aniquilación fuc consecuencia prácticamente necesaria de la ambición sill límites de enriquecimiento por parte de los europeos. Más tarde, cuando se empezó a agotar ese instrumento de enriquecimienlo, se esclavizó a negros africanos para que fungieran como fuentes de energia. Y ése fue el hecho fundante en las relaciones entre los europcos y los pobladores de aquel mundo nuevo, y que explica, en buena parte, lo ocurrido a lo largo de estos cinco siglos.

La Española muestra, pues, que hay verdugos. $Y$ por lo que loca a la leorización de los dercchos humanos, de La Española se aprenden varias cosas: cl sueño de inhumanidad que impide exclamar el "no hay derecho", la busca de justificación tcórica para conculcar derechos y las consecuencias reales de la depredación original.

b) El suevio de inhumanidad. Mucho anles de que comenzasen los debates leóricos en España, en el lugar de los hechos tuvo lugar la reacción primaria: “¡no hay derecho!”, y hubo también unos primeros intentos de fundamentarla. Recordemos la conocida reacción de fray Antonio Montesinos, en 1511, en la isla de La Española:

Todos cstáis en pecado mortul y en él vivis y morís, por la crucldad y lirania que usáis con estas inocentes gentes. Decid, ¿con qué derecho y con qué justicia tenéis en tan cruel y horrible servidumbre a estos indios? ¿Con qué auturidad habéis hecho lan detestables gucrras a estas genles que estaban en 
sus tierras mansas y pacificas, donde tan infinitas de ellas, con muerte y estragos nunca oídos, habeiis consumido? ¿Cómo los tenćis tan opresos y fatigados, sin darles de comer ni curarlos en sus enfermedades, que de los excesivos trabajos que les dais incurren y se os mueren, y por mejor decir, los matáis, por sacar y adquirir oro cada día? Estos ¿no son hombres? ¿No tienen ánimas racionales? ¿No sois obligados a amarlos como a vosotros mismos? ¿Esto no entendéis? ¿Esto no sentis? ¿Cómo estúis en lanta profundidad de sueño tan lelárgico dormidos? II.

El texto usa implícilamente el lenguaje de derechos humanos: con qué derecho, con qué justicia, con qué autoridad. Y los fundamenta: no se puede tratar así a los indios porque lienen ánimas racionales, son seres humanos. Lo más importante, sin embargo, es que el texlo expresa la experiencia primordial: los dominicos captan "la cruel y horrible servidumbre". Esto que debiera ser evidente, los españoles o no lo caplan o prescinden de ello o lo encubren. $Y$ ocurre de forma primaria: “¿cómo estáis en lanta profundidad de sueño latn letárgico dormidos?".

La metáfora de "estar dormido" no es usada aquí como disculpa, sino para mostrar la honda raiz del problema. Expresa una realidad quasi física, no sólo epistemológica o moral, y es la máxima dificultad para captar la realidad: en este caso, la existencia de víctimas producidas por verdugos. "Despertarse" es necesario, pero es lambién difícil, casi imposible, y por cllo epocal, como to proclamó Kant cuando exigió "despertar del sueño dogmático" (tener el coraje de pensar por cuenta propia y no delegar la tarea en otros) para poder ser simplemente humanos. Ese despertar es un cambio real de paradigma, un "ver" las cosas de manera completamente distinta. Y ese despertar, como veremos, sigue siendo problema fundamental en la aclualidad.

c) Jussificación de la conculcación de los derechos. Li denuncia de que hay víctimas llevó a un debale teórico sobre quién tiene derechos, si los curopeos o los indígenas, y qué derechos liene cada uno de ellos. Montesinos, Las Casas y olros argumentaron en favor de los indígenas, es decir, teorizaron la experiencia original de "no hay derecho". Pero la argumentación en favor de los derechos de los europeos fue mucho más abundanle y desde muy diversos trentes.

Antropológicamente se asentaba la inferioridad humana de los indios, llegando a negarles alma y humanidad. Eticamente se aducían las malas y perversas costumbres de los indios, lo cual no sólo permitía sino que exigía que se les sometiera para liberarlos de ellas. Desde la filosofia politica se afirmaba que en aquellas tierras no había dueños legítimos, y por ello los europeos legítimamente las podían conquistar. Eclesiásticamente se aducían las cuatro

11. Citado en Barlolomé de Lis Casas, Itisıoria de las Indias, según la edición de la BAC, Obras escogidas II, Madrid, 1958, p. 176. 
bulas de Alejandro $\mathrm{Vl}$, promulgadas poco después de 1492, en las que se delimitaban las zonas de dominio de españoles y portugueses - para la evangelización-, pero dominio al fin de cuentas. Teológicamente se afirmaba que Dios habia concedido a los españoles aquellas tierras o porque ésa había sido su providencia o como premio por sus luchas contra los infieles durante la reconquista 12.

Y hay que señalar también que en el debate hubo modos muy distintos de argumentar -recordar lo cual es importante pues, en lo sustancial, el problema puede persistir hasla el día de hoy. Para defender el derecho a hacer la guerra a los indios Sepúlveda ulilizaba a Aristóteles, mientras Las Casas replicaba: "Mandemos a paseo en esto a Aristóteles"13, y lo pudo decir porque él estaba activamente en la realidad y afectado por ella. Su pensamiento "está elaborado por alguien inserto en ella. Y su modo de estar en la realidad le permite razonar sobre asuntos de Indias con mucha más lógica y más acerladamente que los leólogos españoles por muy célebres e ilusires que sean"14. Asi lo reconocen también G. Gutiérrez15 y F. Fernández Buey's.

Lo que hemos llamado experiencia primaria no sustituye a la argumentación teórica, pero le otorga solidez, y sin esa experiencia la argumentación no está fundamentada sobre roca, ni encuentra dirección adecuada. El "estar alli", el conocer las cosas "de vistas", no sólo "de oídas", el argumentar, también con la realidad —como lo hemos dicho del método teológico-, es insustiluible. Pero sigue siendo difícil, y no sólo por razones psicológicas o éticas, sino por otras más fundamentales y estructurales. $Y$ es que los que dan la vida por supuesto tienen que hacer un esfuerzo inmenso para "eslar en la realidad", no sólo ante su concepto o su idea. Estando en la realidad de las víctimas se pueden teorizar los derechos de los pueblos porque de algún modo, con todas las analogías del caso,

12. Y también se argumentó en favor de una evangelización antievangélica, lo que a veces llegó a extremos escandalosos, como lo muestra el siguiente texio del Parecer de Yucay de 1571. "Asi digo de eslos indios que uno de los medios de su predestinación y salvación fueron esias minas, tesoros y riquezas, porque vemos claramente que donde las hay va el evangelio volando y en competencia, y a donde no hay csla dole de oro y plata, ni hay soldado ni capilán que quicra ir, ni aun ministro del evangelio... Luego. buenas son las minas entre cstos hárbaros, pues Dios se las dio para que les llevasen la fe y cristiandad. y conservación ell ella, para su salvación. Tomado de Josiene Chinesc, Historia y cullurn, Linsa, 1970. p. 142.

13. F. Fernández Buey, La gran periurhacion. Discurso del indio metropolitano. Barcelona. 1995, p. 159.

14. J. Vitoria, "Diversidad cultural y cvangelio de los pobres". Revista Latinoamericana de Teologia 42 (1997) $27 \%$.

15. En busca de los pobres de Jesucrisio. El pensamiento de Bartolomé de las Casas, Salamanca, 1993.

16. Véase el libro citado en là nota 13. 
estamos entre las víctimas. Pero es estructuralmente difícil, como lo muestra el primer mundo en general, y ésa es una de las grandes lecciones de La Española.

d) Progreso y fracaso en derechos humanos: el concepto y la realidad. Los dominicos de Salamanca elaboraron el derecho de gentes, pero la praxis de la conquista dejó como establecido y normal el uso de conquista y depredación de otros pueblos - praxis que, en diferentes formas, llega hasta el día de hoy, aun con una legislación avanzada sobre derechos humanos. Desde entonces, a pesar de las protestas de un Las Casas y las teorías de un Vitoria, curopeos y norteamericanos invadieron militar, económica, cultural y religiosamente -más o menos según los casos- los continentes de Asia y Africa, y siguieron invadiendo América Lalina. Y fue palideciendo la experiencia primaria de indignación y compasión —de lo cual, en occidente, lambién fueron responsables, en buena parte, las culturas y religiones.

Han tenido que pasas siglos (para los cristianos prácticamente hasta Medellín en 1968) para ver las cosas de olra manera. En las conocidas palabras de Ignacio Ellacuría, se ha tergiversado sistemáticamente lo ocurrido hace cinco siglos, y esa lergiversación es, en mi opinión, una de las razones importantes de la inadecuada, encubridora y en cualquier caso insuficiente teorización actual de los derechos humanos de los pueblos oprimidos.

Lo que 1492 puso al descubierto, dice Ellacuría, no lue América, que quedó encubierta, sino España (y la Iglesia católica romana). Dicho en forma de tesis, "es cl tercer mundo el que descubre al primer mundo en sus aspectos negativos y en sus aspectos más reales... También hoy podemos decir con loda verdad que el primer mundo se acerca al tercero, globalmente, de esa misma forma y con esas mismas intenciones. Y también viene con un ropajc ideológico que no pretende otra cosa sino encubrir, de una manera 'bonita', sus intenciones reales"17.

La lección es importante. Los avances teóricos en el derecho siempre son útiles por su naturaleza, pero se deben asegurar dos cosas. Una es que scan avances desde la perspectiva de las víctimas. Y la otra, que esos avances no sean cooptados - como ocurre hasta el dia de hoy, y en asuntos muy gravespara defender veladamente lo adquirido o adquirible por los más fuerles. Por ello es importante ser conscientes de la realidad mayor en que se inscriben los avances concretos de los Jerechos humanos. ¿No es una ilusión pretender que avancen los derechos alrededor de la vida, por ejemplo, inientras se refuerza un neoliberalismo omnipresente?

17. "Quinto centenario de América Latina. ¿Descubrimiento o encubrimiento?, Revista Latinoamericana de Teologia 21 (1990) 272s. 


\section{La exigencia actual: escuchar el clamor de "los pueblos crucificados"}

Tercera proposición: En el mundo actual hay avances importantes en la formulación de los derechos individuales, pero persisten las víctimas, sobre lodo en forma de "pueblos crucificados". Además, se adormece la conciencia, como si hubiésemos llegado al fin de la hisloria, y no hay a quién pedir cuentas. Ante eslo, hay que jerarquizar los derechos humanos, comenzando con la vida, hay que luchar para que sean realmente universales y, lo mís imporlante, hay que repensar el concepto de "derechos humanos" para que tengan también como sujeto primario a las mayorías populares y a los pueblos.

En el mundo actual, tras dos siglos de revoluciones, se han formulado derechos humanos en generaciones sucesivas. La primera generación reivindicó los derechos polílicos y civiles; la segunda, los derechos económicos, sociales y culturales; la tercera —-todavía en pleno desarrollo-, los derechos a la paz, a la calidad de vida, a un medio ambiente saludable, a la libertad informática... Todo esto es sabido, y ha llevado a una mejoría de la vida de muchas personas. Sin embargo, la realidad global del mundo, vista desde "lo prinigeniamente humano", la vida de los pueblos, es un desastre. Y es que el ámbito de los "derechos humanos" no es adecuadamente el ámbito de "la totalidad de to humano", y por ello, defender y hacer avanzar aquéllos no significa necesariamente defender y hacer avanzar ésta. Hay, pucs, avances en "derechos humanos", pero persiste, cuando no se agudiza, la crisis de "lo humano". Captar y aceplar esta distinción nos parece esencial para teorizar más adecuadamente lo que son "derechos humanos".

No hay que ignorar, por supuesto, dos siglos de reivindicaciones, sino que hay que profundizarlas y ampliarlas. Pero, según lo dicho, hay que añadir dos cosas. Una es complemensar materialmente esa tradición con la consideración de "lo humano", que incluye esencialmente dos cosas: la vida y el ser familia humana. La otra es repensar formalmente, incluso lo ya adquirido en las tres generaciones de derechos humanos, desde la perspecliva de las víctimas -la hermenéutica que ofrecen los pueblos crucificados.

Desde esta perspectiva y desde lo que hemos analizado en el primer apartado, queremos hacer las siguientes reflexiones que ayuden a iluminar, modestamente, algunos aspectos de una adecuada teorización de los derechos humanos.

\subsection{El hecho fundamental: cómo está "lo humano" en los pueblos crucificados}

La expresión actual "pueblos crucificados" puede sorprender -y molestar-, sobre todo porque pondría a nuesiso sigio en línea con la esclavitud en Egipto y 
con los desmanes cometidos en América el siglo XVI. Descle una perspectiva cristiana, sin embargo, y también desde una honrada perspectiva histórica, nada hay de exageración, aunque haya que precisar las cosas. En este final de siglo ha habido avances importantes en los derechos humanos, pero lampoco hay que olvidar que este siglo ha sido, como dice Hanna Arendt, el más cruel en la historia de la humanidad: Auschwilz, Goulag, Hiroshima, Vietnam, Ruanda, Bosnia, las masacres en Guaternala, Haiti, El Salvador, los desaparecidos de Argentina... Una vez más, e inocultablemente, surge el "ino hay derecho!". La Declaración de 1948 quiso remediar la situación, pero "el siglo más cruel de la historia" siguió su curso en forma de violencia —más de 130 guerras después de la segunda guerra mundial, todas ellas, con alguna excepción, en el tercer mundo, más la represión y el terrorismo - sobre todo el de Estado. $Y$ persiste y aumenta la violencia lenta de la pobreza, de la exclusión, del subdesarrollo.

"Pueblo crucificado" no es, pues, lenguaje puramente metafórico, y además es necesario y esclarecedor para conocer cómo está "lo humano". Desenmascara el inocente lenguaje geográfico de "tercer mundo", "el sur". y el de eufemismos encubridores como "países en vías de desarrollo" o "democracias incipientes". Expresa to esencial de "lo inhumano", pues cruz significa muerte, despreciable por cierto, reservada a esclavos $y$ alborotadores, $y$ a eso es a lo que está sometido el tercer mundo: a la muerte lenta que produce la pobreza injusta y a la muerle violenta que acaece cuando los pobres quieren simplemente vivir (necesidad vital que es lo que está casi siempre en el origen de las "revoluciones"). Y a esto hay que ańadir, en este fin de siglo, la muerle por "inexistencia", el surgimiento de una subespecie humana que ya no cuenta, ni siquiera como mano de obra barata para ser explotada, con lo cual la población del lercer mundo se está convirtiendo no ya en población que puede ser explolada, sino en población sobrantelt. Geopolíticamente, al tercer mundo se le está adjudicando el papel de basurero tóxico del planela. Bien está, pues, hablar de cruz'19.

Lo que acabamos de decir se entiende por sí mismo, sin necesidad de conceptuarlo en términos de derechos humanos, y su gravedad proviene de la realidad en si misma, no de que se haya conculcado la legislación sobre los derechos humanos. Sin embargo, si se quiere formular la renlidad de los pueblos crucificados en conceptualización y lenguage de derechos humanos, quizás podamos decir lo siguiente.

18. "Lo que ya uo se necesila es la mayor parle de la población del tercer mundo" F. Hinkelammerı, La crisis del socialismo y el tercer mundo, San Josć, 1991, p. 8.

19. Para los cristianos, el término es importante porque remite al lipo de mucric que dieron a Jesús, con lo cual estos pueblos se le asemejan en algo fundamental. Ya Barlolomé de Las Casas decia: "Yo ucjo en las Indias a Jesucristo nucsiro Dios, alligićndolo y abofelcándolo y crucificándolo, no una sino millares de veces, cuando es de pirte de los españoles que asuelan y destruyen aquellas gentes", op. cii.. p. $51 \mathrm{lb}$. 
a) En nuestro mundo es conculcado, masiva y cruelmente, el derecho fundamental (el "meta-derecho" a la vida que tienen los pueblos oprimidos). Los pueblos crucificados son producidos y no son simples productos de la naturaleza. La relación entre pobreza y riqueza, entre subdesarrollo y desarrollo, no es causal, sino que el mundo desarrollado está basado sobre una acumulación originaria, posibilitada por la explotación a los países pobres. $Y$ en la actualidad, su progreso depende, en buena medida, de la explotación infligida a los países subdesarrollados. Digámoslo con un sólo dato: los países pobres con el pago de la deuda externa han financiado a los países ricos el equivalente a seis planes Marshall (Susan George).

b) La situación de la humanidad es de clamorosa desigualdad20. Según datos de Naciones Unidas, en 1960), la relación entre ricos y pobres era de 1 a 30, y en 1990, de 1 a 60 . Y la relación entre los más ricos de los ricos y los más pobres de los pobres era de 1 a 180 . Los recursos que consume un niño de Estados Unidos son 420 veces más que los que consume un niño en Etiopía. Eduardo Galeano lo ha dicho gráficamente: "un estadounidense vale lo que cincuenta haitianos". Y se pregunta, como para sacudir los cimientos de nuestra civilización, "qué ocurriría si un hailiano valiera lo que cincuenta norteamericanos".

Esła desigualdad entre pueblos y naciones, es en sí misma inaceptable, y más inaceptable porque hoy es posible su superación. De ahí que "el estado del subdesarrollo es en sí mismo y en relación con estados de desarrollo una flagrante violación de la solidaridad humana, esto es, de la naturaleza misma del fundamento de los derechos humanos y lleva consigo la permanente violación de esos derechos"2ı. La parábola del rico Epulón y el pobre Lázaro describe a cabalidad, en lenguaje jesuánico, la realidad de nuestro mundo. En lenguaje del derecho existe un descomunal agravio comparativo.

c) A la Calta de solidaridad con los pueblos crucificados se añade la indefensión de éstos. Más allá de la relórica, prácticamente casi lodos los poderes de este mundo ignoran eficamente a los pueblos crucificados, históricamente quieren aprovecharse de ellos y, si es necesario, suelen estar en contra de ellos: las oligarquías, el capital y la banca mundial, los ejércitos, muchos gobiernos y partidos políticos. Los medios de comunicación, los sindicatos, las iglesias y las universidades tampoco suelen extremar sus desvelos para defenderlos, si es que no se suman al grupo anterior, aunque existen excepciones. No hay instancias que otoguen garantias de vida a los pueblos.

20. Véase Luis de Sebastián, Mundo rico, mundo pobre. Pobreza y solidaridad en el mundo de hoy. Santander, 1993.

21. 1. Ellacuría, "Subdesarrollo y dcrcchos humanos", Revista Latinoamericana de Teología 25 (1992) 4. 
Con la nueva configuración geopolítica del mundo, crece todavía más la desprotección de los pueblos pobres. Con la caída del este, el tercer mundo ha quedado sin remedio a merced del capital22, aunque Juan Pablo II recalque en sus encíclicas la superioridad del trabajo sobre el capital. $Y$ por ello, cuando se habla del siglo $\mathrm{XXI}$, se lo describe no ya en términos de este-oeste, sino de norle-sur. Como se ha escrito, el siglo XXI ya ha comenzado, y su hecho fundante es "el norte contra el sur"2?. Y a esto hay que añadir que si el "primer mundo" sulía fungir como modelo para el tercero, y por cllo el capitalismo estaba interesado en mostrar su rostro humano, ahora el capitalismo de los paises centrales ya no se preocupa - no tiene necesidad- de "mostrar algún rostro humano" 24 .

\subsection{Seguimos "en sueño letárgico dormidos"}

El "sueño" de La Española persiste en nuestro mundo por diversas causas y Je diversas formas. J. B. Melz dijo poco después de la euforia Iras la caida del muro de Berlín que "se está difundiendo una posmodernidad colidiana de los corazones que arrumba la pobreza y la miseria del llamado tercer mundo en una mayor lejanía sin semblante"25. En la actualidad se extiende un ambiente cultural, filosófico incluso (llámesele posmodernidad, con todas las precisiones que se deban hacer, pensamiento light, etc.) que, a la hora de la verdad, ignora a las víctimas, cicrtamente no las hace centrales y no se remite a ellas para juzgar avances o retrocesos de este mundo26.

22. En unas notables palabras lo dijo Monscñor Rivcra, arzobispo de San Salvador: "Con la caida del socialismo real. la Iglesia scrá la única que scguirá luchando por el bien integral de los más pobres de los pobres", Caria a las /glesias 236 (1991) B.

23. X. Gorosliaga, “Ya comenzó el siglo XXI: cl norlc conira cl sur", Envio 116 (1991) 35.

24. F. Hinkelammert, "El huracán de la glubalización: la exclusión y la destrucción del medio ambientc vistus Jesde la Icoria de la dependencia", Economia informa 255 (1997), p. 14. El primer mundo cslí todavia fundamentalmente en cl norte, pero su corrclato no es ya simplemente el sur, sino los cxcluidos.

25. "Tcologia curopea y tcología de la libecración", en J. Comblin, J. I. Gonzílcz Faus, J. Sobrino (cds.), Cambio social y pensaniento cristiano en América Latina, Madrid 1993, p. 268.

26. Para describir estc ambicnte del cspíritu de nuesiro ticmpo basicn csias palabras de Pedro Cassaldáliga, que, al menos Jeídas desde El Salvador, ponen cl dedo cn la llaga: "Algunos creen que ya es hora de cambiar nuestros paradigmas. $Y$ hasla les parece que los mártires estorban en esta memuria postmoderna o posimilitante. Al airc de la decepción. amigos y encmigos vienen lanzando tres preguntas provocadoras: ¿qué queda del socialismo?, ¿qué queda de la teologia de la liberación?, aqué queda de la opción por los pobres. Espero que no acabemos pregunlandonos qué queda del cvangelio", "El cucrno del jubilco", Carta a las lglesias 393 (1998) 8. Espero, añadimos nosotros, que no acabenos preguntándons "qué queda de las víctimas". 
- Peor aún, se ha popularizado e introyectado un lenguaje positivo $-y$ triunfalista - para describir a nuestro mundo. El mundo es ahora una aldea planetaria, globalizada, y hemos llegado al final de la historia27. Se admite que hay problemas, por supuesto, $y$ que hay que avanzar. Pero pareciera que la humanidad hubiese encontrado el camino definitivo, al menos por ser el único, para llegar a la meta28. Hugo Assmann avanza una tesis todavía más radical: no hay que enfocar el problema del mercado moralistamente - enfoque habitual de la izquierda, insuficiente y equivocado-, sino desde la euforia de la derecha. Esa euforia se expresa en la retórica sobre el mercado como "buena nueva", "evangelio jubiloso", "descubrimiento feliz". $Y$ "cuando los opresores se sienten bienhechores", dice Assmann, "cs porque creen en un evangelio inconmovible"29. Una vez que el mercado es elevado a evangelio, ya no se puede preguntar si es eficiente, en qué y para quién. Se sustrae a toda verificación. Y con ello se equipara a la divinidad: no necesita justificación.

Hay otros aspectos de la cultura occidental que contribuyen al adormecimiento. Desde una perspectiva ideológica, se rehuye aquello que exprese conflicto o crítica radical —siendo así que las víctimas lo expresan por necesidad. Desde un punto de vista cultural, ni la indignación ni la compasión son tenidas como aclitudes y valores primarios - siendo así que conslituyen la experiencia primaria anle las víctimas-, pues no convergen con los que ahora se propician: tolerancia, diálogo, consenso, debate civilizado. Desde un punto de vista eclesial, decae la denuncia del pecado social y de la injusticia — siendo así que las víctimas son su produclo. Desde un punto de vista teológico, poco se habla - con convicción- del Dios de la vida y de la justicia, del Jesús que optó por los pobres en contra de sus opresores - siendo así que para las víctimas ése y no olro es su Dios y su Cristo. Y tampoco se habla de los ídolos existentes (acumulación de capital, de poder y de recursos, además de nacionalismos y einocentrismos) - siendo asi que su realidad se muesira en producir víclimas. La conclusión es que, siendo la realidad más clamorosa, las víctimas no son centrales a la hora de pensar una adecuada configuración de este mundo ni un nuevo orden mundial; mucho más lo son el mercado y el consumo (de lo cual se

27. "El fin de la hisloria no significa el lin de los acontecimienlos mundiales, sino el linal de la evolución del pensamiento humano respecto a los principios orientadorcs... Es el término de la cvolución idcológica de la humanidad y de la universalización de la democracia liberal occidental como última forma de gobierno", aclara Francis Fukuyama. Véasc hugo Assmann, Las falacios religiosas del mercado, edición resumida de Cristianisme i Juslícia, Barcclona, 1977, p. 15.

2B. "Como aparentemente ya no existen espacios de soluciones alternativas, la globalización y el sometimicnto a clla aparcecen como la única realidad", F. Hinkclammert, op. cil., p. 11.

29. Cfr. op. cil., p. 20. 
habla públicamente), y la producción de armamento (sobre lo cual se guarda silencio). El pathos de indignación y misericordia que genera la experiencia de las víctimas no parece ser hoy "políticamente correcto".

La ceguera, la indiferencia, el éxtasis eufórico o el sueño letárgico, son recurrentes en la historia en cosas sumamente graves, y el hecho no deja de impactar. Ante la "condenación histórica" de víclimas y excluidos - dos tercios de la humanidad-, aceptada práclicnmente como cosa natural por nuestro mundo, vienen a la mente $\rightarrow$ al menos a personas de mi generación-con qué naturalidad se hablaba antes de la "condenación etcrna" de, posiblemente, millones de seres humanos. Más aún, cómo se defendían tesis tcológicass sobre la predestinación del ser humano: al ciclo y al infierno. Todo ello reflejaba una idea de Dios, y por ello, dada la ultimidad de Dios, reflejaba un "así son las cosas y no hay nada que hacer" —que es lo que ahora nos interesa recalcar. J. I. González Faus lo ha recordado, comparando el espírilu del capilalismo con el espíritu del jansenismo:

La brutalidad del Dios jansenista, que condena a quienes quiere y queda indiferente o satisfecho anle su condena, llevó a Jansenio a escribir que "los réprobos sólo nacen y viven para utilidad y ventaja de los elegidos". Si eso puede decirse tranquilamente del destino último y total de los hombres, ¿quć tendrá de extraño que también en esta vida la inmensa mayoría de los hombres nazca y viva sólo para utilidad y ventaja de unos-pocos privilegiados? ¿O que esos pocos, en lugar de soportar el juicio bíblico de condena por su inhumanidad y su falta de entrañas, detenten la cliqueta capitalista de ser los elegidos de Dios y los defensores de Dios??30.

Es lo que ocurre en presencia de los pueblos crucificados: se invoca implícilamente alguna estructura metafísica de la realidad según la cual "así son las cosas". Y no acabamos de desperlar del sucño, porque, ahora ya no es un simple sueño - realidad antropológica del ser humano-, sino realidad melalísica inmulable. Ya lo dijo Jesús: "no harán caso ni auncque un muerto resucile".

\subsection{La falaciu de la universalidad de los derechos humanos}

En el mundo occidental, aunque formulados universalmente. de hecho desde su origen los derechos humanos beneliciaron a unos mis que a otros - lo que ocurre hasta el dia de hoy. Existe, pues, desde el principio una parcialidad, pero de signo contrario a la que hemos mencionado: los derechos humanos, en

30. "Vcinticinco años de la teologia de la liberación: teologia y opción por los pobres". Revisı Latinoamericana de Teología 42 (1997) 232. 
general, son patrimonio de poderosos más que de pobres. De hecho, de ellos se suclen aprovechar más los opresores que los oprimidos.". La conclusión es clara:

De poco sirve ser hombre para poder contar con to necesario para sobrevivir, para tener una vivienda minima, para que los niños enfermos tengan un mínimo de medicinas, elc. Es menester ser norteamericano, europeo, soviético o japonés para poder contar con los recursos suficientes para sobrevivir y para disfrutar de los recursos que Dios, a través de la naturaleza y de la razón, puso en el mundo pará todos. Es, de hecho, más importanle ser ciudadano de un país poderoso y rico que ser hombre, aquello da más derechos reales y más posibilidades efeclivas que esto. Queda asi rota la solidaridad humana?3.

Los derechos humanos se basan en el presupucsto de que la especie humana es también esencialmente familia, de que todos debemos propiciar la vida de todos. Lo que tenemos ahora, sin embargo, es todo lo contrario. La actividad económica general hoy está montada para bencficiar de una manera egoista y desproporcionada a los países industrializados (L. de Sebastián). "No ha existido en la historia, ni siquiera en la época colonial, una bipolarización tan extrema del mundo"33.

La universalidad, que le es esencial a la concepción occidental de los derechos humanos, no existe. $Y$ hay que preguntarse incluso si puede exislir, pues, lal como están las voluntades, ¿es posible que todos los seres humanos dis[ruten del derecho al trabajo, a la verdad de la información. a la libertad de expresión. a un medio ambiente saludable y a lantas otras cosas, sin que eso se convicrta en una seria amenazada al orden económico, militar y político constitujdo? Nos tememos que no. Un verdadero disfrute universal de los derechos humanos es, históricamente, una amenaza para los grupos y los pueblos poderosos. Por ello, es muy lógico que -a pesiar de la retórica reinante- no estén seriamente interesados en la umiversalidad de los dercchos humanos.

31. Al comentar los logros de finales del siglo XVIIl dice Ellacuría: "Aunque idcalmente sc presentan como derechos humanos, son dercehos limitados a una forma determinada de ser hombres (freemen ingleses. hombres hlancos del huen pueblo de Virginia, burgueses (ranceses, c(c.). Tan es asi, que ni siquicra alribuyen csos derechos a quiencs conviven con cllos (campesinos ingleses o franceses. negros y esclavos norteamericanos, etc.), por más que no se les nicgue su carácler de humanos", "Historización"... p. 591.

32. I. Ellacuría, "Subdesarrollo y derechos humanos", Revisfa Latinaamericana de Teologia 25, (1992), 5 s.

33. X. Gorosliaga, op. cit. p. 36. 
La lección es que, aunque necesario, el avance en la formulación y fundamentación teórica de los derechos universales es insuficiente. Faltan en el mundo desarrollado la indignación y la misericordia ante la crueldad causada o tolerada por esos mismos países. Falta la parcialidad de la perspectiva para no confundir universalidad con lo que en realidad es sólo el 25 ó 30 por ciento de la humanidad. Falta pensar los derechos humanos desde la vida de los pueblos, no desde necesidades que pueden ser secundarias con respecto a aquélla. Falta poder denunciar a los responsables de que se viole el derecho fundamental a esa vida. Falta la posibilidad de pedir cuentas a esos responsables y que éstos las den.

\subsection{A quién pedir cuentas}

"Derechos" humanos presupone responsabilidad en inslancias que los deben garantizar. La accountibility es esencial a los derechos humanos y el problema es a quién pedir cuenlas. Simplificando las cosas, en el ámbilo de los derechos humanos convencionales esa instancia es el Estado. Este puede (y según las circunstancias suele) garantizar los derechos humanos de la primera generación, los derechos individuales y políticos. Pero no garantiza ni puede garantizar de la misma manera los derechos económicos de la segunda generación, es decir, no garantiza la vida - aunque pueda ayudar. $Y$ es que "en la idea de la libertad política y de la libertad civil no está implicada idea alguna de la justicia distributiva... El derecho es únicamente un medio, absolutamente desvinculado de los fines de la justicia"34. El estado se responsabiliza del derecho, pero no de la justicia.

E] Estado social no tiende a eliminar los presupuestos del proceso económico capitalista, sino que, única y exclusivamente, corrige los efectos de la desigualdad sobre el plano de la distribución de la riqueza producida... Mientras que al sistema de las empresas se le conserva el poder de dirección del proceso económico, al Estado se le asigna la tarea de crear un sistema de "seguridad social" destinado a asegurar condiciones de vida más igualitarias 35 .

¿A quién se puede, pues, pedir cuentas? O dicho de otra manera, ¿no se cae en una especie de equívoco al usar el mismo término "derechos" y aplicarlos a los derechos políticos y civiles, con una instancia que los debe y puede garantizar, y que está somelida a verificación de si lo hace o no, y a los derechos económicos, con una instancia que, en definitiva, sólo puede regular lo

34. Pictro Barceliona, "Los sujelos y las normas. El conceplo de Estado social", en Enrique Olivas (cd.) Problemas de Iegimitidad en el Estado Social (Madrid 1991) p. 31 .

35. Ibid., p. 33. 
que otros hacen, pero sin que a esos olros se les pueda exigir que garanticen la vida?

Esos otros, el aparato económico, financiero, no se sienten obligados a garantarizar la vida de todos. Más aún, invocan derechos - la liberlad- para no tener que someter su modo de proceder a una normativa que genere vida para las mayorias. Y pueden ocurrir cosas peores. En el seno de la Organización de Cooperación y Desarrollo Económico (OCDE) se está elaborando —en absoluto secreto 36 - el Acuerdo Mullilateral sobre Inversiones (AMI). Por lo que toca a derechos y obligaciones, el acuerdo preve un tratado de comercio que autoriza a las empresas multinacionales y a los inversores a llevar ante la justicia a los gobiernos por cualquier acción de éstos que tuviera como efeclo una reducción de sus beneficios. En ese acuerdo, Jos derechos están reservados a las empresas y los inversionistas internacionales, mientras que los gobiernos asumen lodas las obligaciones. Así, estos tienen la obligación de garantizar el "pleno disfrute" de las inversiones, y los inversionistas y las empresas tienen derecho a denunciar cualquier política o acción gubcmamental (medidas fiscales, disposiciones sobre el medio ambiente, la legislación laboral, las reglas de protección al consumidor) que consideren perjudiciales, y pueden exigir indemnizaciones en caso de intervenciones gubernamentales que restrinjan sus beneficios ${ }^{37}$.

En ésas estamos. Y si eso ocurre dentro de los estados, cuanto más ocurrirá a nivel planetario. ¿A quién se puede pedir cuentas de los 36 millones de seres humanos que mueren de hambre anualmente? ¿A quién pueden pedir cuentas los pueblos oprimidos? ¿A quién pedir cuentas cuando estallan las guerras, si el armamento mundial es controlado por el consejo de seguridad de Naciones Unidas?.'. Y . si no se puede pedir cuentas a nadie, ¿qué esperanza tienen los pueblos?.39.

36. Véase Lori M. Willach, "El nuevo manifiesto", en Le Monde Diplomatique, febrero de 1998, cdición cspañola.

37. "Mientras los estados están dando, en todas partes, cortes a sus programas sociales, se les pide que aprueben un programa mundial de asistencia a las firmas transnacionalcs", ibid.

38. "El 90 por ciento de las armas vendidas entre 1988 y 1992 lo fucron por los cinco miembros permanentes del consejo de seguridad (p. 42), los cuales, además, no hun firmado muchos de los pacios relativos a los derechos humanos propucslos por Naciones Unidas (p. 39)", J. I. González Faus, "La paz: nuevo nombre del Jesarrollo". ECA 550 (1994) 830. El autor comenta y cila a V.. Fisas, El Desafio de Naciones Unidas ante el mundo en crisis, Barcclona, 1994.

39. "La corle suprema de juslicia de Naciones Unidas está casj inćdita: en sus cuarenla años de existencia sólo ha tratado 60) asuntos y cuando falló contra el minado de los pucrtos de Nicaragua por parte de Estados Unidos, ésıc retiró su aceptación de la jurisdicción de la cortc suprema (p. 63)", ibid., p. 830. 
El pedir cuentas ha sido una dimensión importanle en la tradición religiosa cristiana. En presencia del mal, de la deshumanización, del no deber ser, se ha pedido cuentas a Dios. Es el problema que en términos técnicos se ha llamado teodicea. No vamos a entrar en él ahora, sino sólo recalcar el hecho. $Y$ a veces se han usado palabras fuertes:

En un mundo en el que la razón y la libertad del ser humano han producido las realidades de este siglo $\mathrm{XX}$, hablar de continuidad entre lo humano y lo divino sólo puede significar que el misterio último de la existencia - Diosno es un Amigo del ser humano sino, más verosímilmente, un Enemigo: Dios crea con el único fin de destruir40.

El lenguaje religioso tiene la ventaja de poder ser audaz, y también honrado, cosa que no suele ocurrir con otros lenguajes. ¿No es el problema de nuestro mundo que el sistema, con loda su retórica, con sus discursos políticos, económicos, militares, no es un "amigo de los pueblos oprimidos"?

Volviendo al lenguaje religioso, a Dios se le puede pedir cuentas, se le puede criticar y se puede rencgar de él. Según la tradición cristiana, sin embargo, por una parte, también Dios, indefensamente, participa de las víctimas y está crucificado. Pero, por otra, anima a luchar por la vida de los pobres, devuelve a la vida al crucificado Jesús, y alimenta la esperanza de los pueblos crucificados. Sea cual fuere la aceplación de esta tradición cristiana, el simbolismo es importante: los seres humanos podemos pedir cuentas, Dios no se desenliende de la realidad crucificada ni se hace sordo a sus clamores. Se pasa de bando y "Dios" llega a ser miembro de este mundo de víctimas.

Este es lenguaje religioso, simbólico y utópico, ciertamente. Pero es que el sistema ni siquiera a nivel simbólico y del lenguaje se preocupa de participar en la realidad de las víctimas. Normalmente las genera. Y es inútil pedirle cuentas.

\section{Una palabra sobre la mística de los derechos humanos}

Terminemos por donde empezamos. En el mundo actual, la situación es paradójica. Por una parle, hay avances en ámbilos concrelos de to humano (libertades, garantías...), lo que ocurre sobre todo en paises en abundancia, y también, en grado mucho menor, en las "bolsas de abundancia" de países pobres. Esos avances no lo han logrado todo, pero han puesto a lo humano en una dirección correcla. Han introducido una tradición de reivindicaciones, la convición y la esperanza de que los cambios, son posibles. $\mathrm{Y}$ han introducido la tradición de compromiso y de lucha, con caídos y mártires. Los derechos humanos muesiran, pues, que ha habido un gran amor. Pero, por otra parte, lodo

40. D. Hollenbach, "Elica social bajo el signo de la cruz". Revisla Latinoamericana de Teologia 37 (1996) 51. 
ello no ha cambiado sustancialmente la inhumana situación de pueblos oprimidos y de mayorías empobrecidas. "Lo inhumano", más que el disfrule de "los derechos humanos", es lo que define la vida de los pueblos oprimidos.

De esto hay que ser conscientes en el mundo actual. Dicho con un ejemplo actual, no es lo mismo que se viole el derecho humano "a la privacidad en el mundo de la informática" que el que las dos terceras partes de la humanidad vivan en pobreza. Por ello, no es lo mismo defender el derecho a esa privacidad que luchar para sacar a este mundo de la pobreza. La conclusión es que la lucha por los derechos humanos, en el sentido convencional, liene que estar inlegrada en la lucha mayor por la vida de los pobres, de las mayorias y los pueblos oprimidos.

Resumiendo lo que hemos dicho, esa lucha debe recoger y mantener el "no hay derecho" ante la siluación del mundo y no permilir que ese grito quede sofocado - la manera más sutil seria excusarse de actuar porque no responde a ninguna formulación concreta de los derechos humanos. Debe hacer central el que los derechos humanos sean pensados y llevados a la práctica como derechos -en plural- de todos, humanos - simplemente por haber nacido humanos y no en países de abundancia. Debe garantizar y posibilitar la vida, sin que el goce de los derechos de unos pocos se convierta en agravio comparativo. Debe desenmascarar una conciencia colectiva adormecida, drogada, que impide ver lo evidente.

Hoy es notable el número de instituciones civiles, religiosas, universitarias que se dedica a los derechos humanos, y eso es una esperanza. Muestra, por una parte, que las instancias que deben velar por ellos con frecuencia no lo hacen, y de ahí la proliferación de estas instituciones. Pero muestra también que hay conciencia de su absoluta necesidad, conciencia que debe ir compañada de creatividad y míslica para no desfallecer en un mundo que, en buena parte, está configurado en contra de los derechos humanos y de lo humano de los pueblos.

De dónde proviene esa mística es cosa a analizar. Por mi parte quisiera terminar con unas palabras de hace ya quince años cuando me pidieron escribir sobre "lo divino de luchar por los derechos humanos". No sabía cómo empezar, y empecé de esta manera, que quizás ilumine también hoy lo que es esa mistica:

¿Hay algo "santo" en el mundo de hoy? ¿Hay algo que exija al hombre con ultimidad, pero que se presenta también como promesa y plenificación? ¿Hay algo que le impida relativizar lodas las cosas por igual, aunque quizá no sepa leóricamente por qué no deba relativizarlas? ¿Hay algo que impulsa a ir más allá del propio yo y de los yos grupales, aunque fuesen buenos, como la familia, el partido, el país, la propia lglesia?

A lo largo de la historia siempre ha habido eso que hemos llamado "lo santo", de forma religiosa o secular. En la actualidad no parece caber duda 
de que la defensa de los derechos humanos se presenta para muchos como algo santo, con ultimidad, exigencia y promesa de salvación. Ciertamente lo es en los países del tercer mundo y lo es también, de diversas formas, en los del primer mundo. Eso santo es la vida de los pobres, la vida de las víctimas41.

La mística de la lucha de los derechos humanos depende en último término de relacionarlos con la vida, y con la vida de quienes son mayorías, pueblos crucificados. Lo que nos hace seres humanos cabales, "santos" - si interesa ese lenguaje-, lo que posibilita que vivamos con dignidad y sin avergonzamos de configurar un mundo cruel, es esa lucha por la vida de las víctimas, corriendo riesgos por ellas y partipando en su realidad. De ese modo podremos sentir el gozo de pertenecer y vivir dentro de la familia humana.

41. "Lo divino de luchar por losderechos humanos", Sal Terrae 856 (1984) 685. El lexlo cslá algo modilicado. 